\title{
Blocking soluble guanylate cyclase could be the present and future of NO/cGMP inhibition for vasoplegia treatment
}

\author{
Paulo Roberto Barbosa Evora(D)
}

See related research by Levy et al., https://ccforum.biomedcentral.com/articles/10.1186/s13054-018-1967-3

Cumulative evidence indicates that NO/cGMP inhibition would make a difference in vasoplegia treatment. Unfortunately, methylene blue (MB) is the only compound we currently have that can be used for this purpose. The effects of $\mathrm{MB}$ are apparent only in the case of nitric oxide (NO) up-regulation, and it is not a vasoconstrictor per se. Blocking the cGMP system "releases" the cAMP system in a kind of "crosstalk," facilitating the noradrenaline vasoconstrictor effect $[1,2]$.

I recently wrote an editorial opinion suggesting this approach as an unexplored therapeutic frontier for the pharmaceutical industry. MB is the oldest drug infused in humans, is cheap, and is not patented for industrial use, but the medical literature insists that it has not been the subject of any sizeable clinical trials, even considering its safety at low doses. However, it is mandatory to use it early, not as rescue therapy [3].

Studies suggest that MB has a potential role in protecting the microcirculation. In an experimentally induced septic shock model in rats, only the combination of norepinephrine (NE) and $\mathrm{MB}$ restored mean arterial pressure to control levels by the end of the 3-h experiment. Intravital microscopy demonstrated better microvascular integrity in the presence of $\mathrm{MB}$, and severe damage to animals that were infused with only NE [4]. Therefore, MB would be an option to prevent direct organ damage from adrenergic agents.

Levy and colleagues wrote an excellent review article about the "past, present and future" of vasoplegia treatment and presented some concerns about MB use [5]. Not considering $\mathrm{MB}$ itself, blocking soluble guanylate cyclase (sGC), the final NO/cGMP messenger, in smooth

\footnotetext{
Correspondence: prbevora@gmail.com
}

Department of Surgery and Anatomy (Division of Cardiothoracic Surgery); Ribeirão Preto School of Medicine, University of São Paulo, Rua Rui Barbosa, 367, Ap 15, Rbeirão Preto, SP 14015-120, Brazil muscle is underestimated and deserves a place in the present and future.

\author{
Abbreviations \\ CAMP: Cyclic adenosine monophosphate; cGMP: Cyclic guanosine \\ monophosphate; MB: Methylene blue; NO: Nitric oxide

\section{Funding} \\ This research received no specific grant from any funding agency in the \\ public, commercial, or not-for-profit sectors.
}

\section{Availability of data and materials \\ The datasets used and/or analyzed during the current study are available from the corresponding author on reasonable request.}

\section{Authors' contributions \\ PRBE contributed to the study concept and design and read and approved the final manuscript.}

\section{Competing interests}

The author declares that they have no competing interests.

\section{Publisher's Note}

Springer Nature remains neutral with regard to jurisdictional claims in published maps and institutional affiliations.

Received: 9 March 2018 Accepted: 29 March 2018

Published online: 20 April 2018

\section{References}

1. Evora PR, Ribeiro PJ, Vicente WV, Reis CL, Rodrigues AJ, Menardi AC, Alves Junior L, Evora PM, Bassetto S. Methylene blue for vasoplegic syndrome treatment in heart surgery: fifteen years of questions, answers, doubts and certainties. Rev Bras Cir Cardiovasc. 2009;24(3):279-88.

2. Evora PR, Alves Junior L, Ferreira CA, Menardi AC, Bassetto S, Rodrigues AJ, Scorzoni Filho A, Vicente W. Twenty years of vasoplegic syndrome treatment in heart surgery. Methylene blue revised. Rev Bras Cir Cardiovasc. 2015:30(1):84-92.

3. Evora PRB. G-proteins agonists and NO/cGMP blockers: unexplored frontiers in the pharmaceutical industry. Arq Bras Cardiol. 2017 Oct;109(4):275-6.

4. Nantais J, Dumbarton TC, Farah N, Maxan A, Zhou J, Minor S, Lehmann C. Impact of methylene blue in addition to norepinephrine on the intestinal microcirculation in experimental septic shock. Clin Hemorheol Microcirc. 2014;58(1):97-105

5. Levy B, Fritz C, Tahon E, Jacquot A, Auchet T, Kimmoun A. Vasoplegia treatments: the past, the present, and the future. Crit Care. 2018;22(1):52. 